\title{
UNIVARIATE AND BIVARIATE VOLATILITY IN CENTRAL EUROPEAN STOCK MARKETS
}

\section{Claudiu Boţoc*}

\begin{abstract}
This paper examines if the volatility exhibits a symmetric or an asymmetric response to past shocks, particularly the relevance of structural breaks for Central European (hereinafter referred to as "CEE") stock markets. In addition, it is of great interest to see if the CEE emerging markets are correlated with other emerging ones, as well as to analyse the correlation with the developed markets, for optimizing investment portfolios. Using a CEE group approach (regional index) and daily data from 2002 to 2015 , the results suggest that markets react differently to similar negative and positive returns, except for the rapid growth period, when the greed sentiment dominates the markets. Furthermore, the structural break dates affect volatility, the highest asymmetric coefficient being recorded for the pre-crisis period. For the bivariate approach, the emerging markets and developed markets indexes provided by the Morgan Stanley Capital International (hereinafter referred to as "MSCl") have been considered and the results suggest that CEE stock markets are correlated with emerging stock markets rather than developed ones. For both pairs, the correlation is consistently higher for the break dates characterized by an increase in volatility, which is in line with the literature that claims that the co-movements increase when international factors dominate the national ones, and influence stock markets.
\end{abstract}

Keywords: volatility, asymmetry, structural breaks, contagion, multivariate GARCH JEL Classification: C32, C58, G10

\section{Introduction}

Gaining benefits from portfolio diversification is viewed as an on-going task which requires seeking abnormal returns in several international stock markets. Financial investment decisions stem from the risk-return trade-off and risks serve as criteria for decision making process. Therefore, as a simple risk measure determined by standard deviation, stock market volatility is a key indicator for several players from these arenas. The importance comes also from regulatory framework, i.e. Basle's accord, where volatility is a variable used for financial risk management (Basel Committee, 2011).

* Claudiu Boţoc, Department of Finance, Faculty of Economics and Business Administration, West University of Timișoara, Timișoara, Romania (claudiu.botoc@e-uvt.ro).

This work was supported by the European Social Fund through Sectorial Operational Programme Human Resources Development 2007-2013, Project No. POSDRU/159/1.5/S/142115, Project "Performance and Excellence in Postdoctoral Research in Romanian Economics Science Domain". Special thanks are addressed to Elias Tzavalis, Dimitrios Asteriou, Cristian Badarinza, Stavros Degiannakis and participants at 1st International Conference in Applied Theory, Macro and Empirical Finance (AMEF 2015) for helpful suggestions on previous versions. Any remaining errors are solely the responsibility of the author. 
There is a consistent strand of the empirical literature dealing with stock markets issues like volatility modelling, forecasting, co-movements, spillover effect or structural breaks relevance. Since examining market volatility could be misleading for GARCH users, it is worth to be noticed that the aim of the paper is exclusively focussed on volatility estimation, rather than forecasting. In this respect, this paper relates to the discussion of studies employing univariate and bivariate GARCH models and the effect of structural breaks. For studies employing other estimation methods (cointegrations, causality, spillover effects, wavelet analysis), or forecasting methods (in-sample, out-of sample), see Demiralay and Bayraci (2015), Dajčman (2013), Horváth and Petrovski (2013), Guidi and Ugur (2014), Harrison and Moore (2012). For instance, in a recent paper that employ Diebold and Yilmaz methodology, Demiralay and Bayraci (2015) explore volatility spillovers between CEE stock markets (Poland, Hungary, the Czech Republic) and developed markets (Germany, USA) or emerging markets (Russia). Even with other methodology, they find that CEE stock markets display higher volatility in times of extreme events, as well as a volatility transmission mechanism among CEE stock markets and the counterparts used.

Stock market volatility has been extensively examined through univariate GARCH models for several developed, emerging and frontier markets. For the case of Central European stock markets (CEE hereafter) either symmetric (Murinde and Poshakwale, 2001), or asymmetric (Patev et al., 2006) volatility was revealed, depending on the sample period and methodology employed. Furthermore, the superiority of asymmetric behaviour has been observed, i.e. volatility increases more after a negative shock than after a positive shock. There could not be ignored the contradictory results encountered in previous empirical findings which constitute the premise for additional work.

Despite the rich body of empirical work that deals with volatility estimation in univariate GARCH model, less attention was given to the potentially sudden shifts in volatility in CEE context. Wang and Moore (2009) tackle this issue through iterated cumulative sum squares (ICSS) and find that when such structural breaks are considered, the persistence of volatility is significantly reduced.

Later, many researchers revealed an increased correlation between national stock markets, particularly after global shocks. The correlation between stock markets is very important for optimizing investment portfolios since it is associated with a form of market integration with specific regulations and the so-called law of one price. Despite its benefits, the law of one price could face specific drawbacks if the investors are exposed to the same structural shocks.

This requires estimating the volatility in the framework of stock market co-movements using multivariate GARCH models. A consistent body of previous studies was focussed on the symmetric multivariate GARCH models, by exploring the links between emerging and developed markets (Wang and Moore, 2008; Syllignatis and Kouretas, 2011; Horváth and Petrovski, 2013). Recent studies allow for asymmetry in conditional correlation dynamics (Wang and Moore, 2008; Gjika and Horváth, 2013).

Using the CCC model for testing the co-movements between four CEE markets (the Czech Republic, Poland, Hungary and Slovakia) during 1994-1998, Kasch-Haroutounian and Prince (2001) find positive conditional correlation only for the pairs the Czech Republic-Hungary and Hungary-Poland. For the BEKK model they find only one unidirectional volatility spillover, from Hungary to Poland. For the remaining pairs, the results indicate that volatility from each market is affected by its own events. 
Wang and Moore (2008) employ a DCC model for testing the co-movements of three CEE markets (the Czech Republic, Hungary, Poland) with respect to the Eurozone over the period 1994-2006. Their results indicate a price spillover effect from the Eurozone market to emerging markets (apart the Czech Republic), but not vice versa. Similar, the asymmetric volatility generated from Eurozone market is transmitted to all emerging markets. Like previous findings, a higher level of correlation is recorded during international events, i.e. Asian and Russian financial crisis, post EU accession.

Syllignakis and Kouretas (2011) analyse the correlation between both Central and Eastern Europe (the Czech Republic, Hungary, Poland, Slovakia, Slovenia, Estonia, Romania) with respect to the USA, Germany and Russia. Using the DCC model and weekly data from 1997 to 2009 they reinforce that stock market correlations increase over time (particularly during the 2007-2009 financial crisis), providing an increase in the portfolio risk. Furthermore, the analysis for the 2007-2009 financial crisis supports the hypothesis of contagion effect due to herding behaviour, while for the Asian and Russian financial crises the hypothesis is rejected.

The same time-increasing pattern in correlation is highlighted by Gjika and Horváth (2013), but the asymmetric effect is partially present. They perform a study for top 3 Central European stock markets (Poland, the Czech Republic, Hungary) for a daily data from 2001 to 2011, applying the asymmetric DCC which is considered more appropriate for examining correlations during financial crisis. Their result suggests that asymmetries in the correlations are not as widespread as in the conditional variances since asymmetric effect is found only in Hungary-Poland pair. However, the value of correlation is very high (0.6-0.7) particularly during the financial crisis. They further investigate the relationship between correlations and volatilities, and highlight a positive association, suggesting that diversification issue is significantly lower for turmoil periods.

However, even though most of previous studies focussed on the correlation of emerging markets from Central Europe with developed markets, evidence on correlations with other emerging markets remains relatively limited. In fact, when diversification has to be considered by individual/institutional investors, it is worth to be examined if such decision could be simultaneously implemented in several stock markets.

In light of this, the main aim of the paper is to examine the stock market volatility for CEE stock markets where specific gaps from the literature will be addressed. Particularly, three issues represent the motivation for the empirical work. First, if the volatility displays an asymmetric response to past shocks, if it reacts differently to similar negative and positive returns. In this respect, the contribution is related to the recent period examined (up to February 2015) in order to reinforce or reject previous findings. Second, if the volatility is affected by sudden shifts, i.e. the presence of structural breaks, given that classical GARCH model overestimates the persistence in volatility if such breaks are ignored. There will be considered several univariate GARCH-M models, as well as recent statistical techniques (Bai-Perron, 2003) that allow for the asymmetric effect in the sensitivity analysis. Third, if the diversification principle could be considered, i.e. if the CEE emerging markets are correlated with other emerging, as well as developed markets. To deal with this, there have been employed multivariate GARCH models, particularly bivariate, that either represent direct generalizations or non-linear combinations of the univariate GARCH models. Finally, it is used a CEE group approach, i.e. a regional index for the CEE stock markets (CETOP 20 Index) which does not restrict to report several univariate and bivariate GARCH models. 
The remainder of the paper is organized as follows. Section 2 describes the data collection and characteristics. The methodology employed is reported in Section 3. Section 4 presents the main results of the study for univariate and bivariate approach, while Section 5 concludes.

\section{Data}

The data consists of daily closing price of CETOP 20 Index (CEE) from the period 30 January 2002 (the day when the index was launched) up to 19 February 2015 ${ }^{1}$. The 3,406 price observations are collected from www.bse.hu. For the bivariate analysis the series was synchronized with daily values of MSCI emerging market index (EM) and MSCI developed market index (DM), for which data have been collected from www.msci.com. The daily return is computed as continuous compounding return: $R_{t}=\ln \left(P_{t} / P_{t-1}\right)$.

It is worth to be noticed that the period considered for empirical analysis covers CEE's pre-accession stage, with specific negotiation process, the accession stage, as well as the financial crisis and euro sovereign crisis impact. Furthermore, the extensive period constitutes the motivation for testing the influence of structural breaks.

The preliminary analysis include the plot of data (Figure 1), where for the price there could be observed several upside and downside trends and for the daily return volatility clustering issue. Furthermore, according to the unit root test considered, i.e. the Augmented Dickey Fuller (ADF) test, the behaviour of the stock prices is characterized by a Martingale process.

\section{Figure 1 | CETOP20 Index Overview}
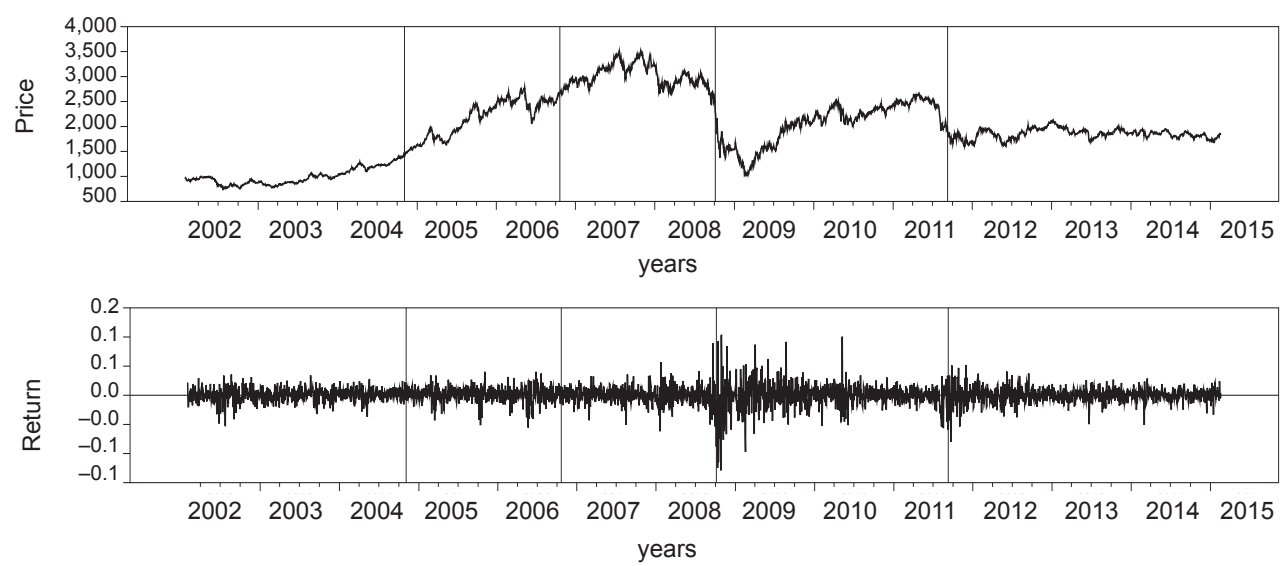

Source: Own calculations.

The stylized facts for daily returns are reported in Table 1 and suggest that all indexes exhibit volatility and have a leptokurtotic distribution. This implies that there is a higher probability for extreme events, very often experienced in financial time series. The unconditional correlation between CEE and emerging markets is 0.682 , higher than

1 The CETOP20 index (Central European Blue Chip Index) reflects the performance of 20 companies with the biggest market value and turnover in the Central European region (Hungary, Poland, the Czech Republic, Slovakia, Slovenia and Croatia). 
in CEE and developed markets. Regarding the extreme values, there could be observed the effect of global financial crisis over CEE markets since the series records both maximum $(10 \%)$ and minimum $(-12.8 \%)$ values during October 2008.

The unconditional non-normal distribution is not rejected by the Jarque-Bera Statistics. Furthermore, the Breusch-Godfrey test (with 4 lags) rejects the null hypothesis of no serial correlation, while the ARCH LM test suggests the presence of ARCH effects in the residuals. This motivates the estimation of conditional variance using a GARCH-M $(1,1)$ model.

Table 1 | Stylized Facts

\begin{tabular}{|l|c|c|c|}
\hline & CEE & EM & DM \\
\hline Mean & 0.000197 & 0.000327 & 0.000178 \\
\hline Std. Dev. & 0.015 & 0.012 & 0.010 \\
\hline Skewness & -0.434 & -0.519 & -0.371 \\
\hline Kurtosis & 11.343 & 11.721 & 11.460 \\
\hline Jarque-Bera & $9,986.19^{*}$ & $10,949.45^{*}$ & $10,237.02^{*}$ \\
\hline Pearson correlation & - & 0.682 & 0.617 \\
\hline BG Test (4) & $5.489^{*}$ & $41.322^{*}$ & $16.156^{*}$ \\
\hline ARCHLM (4) & $182.441^{*}$ & $248.423^{*}$ & $191.863^{*}$ \\
\hline Number of Observations & 3,406 & 3,406 & 3,406 \\
\hline
\end{tabular}

Note: BG is Breusch-Godfrey test for serial correlation with 4 lags; ARCHLM is the Lagrange multiplier test for autoregressive conditional heteroskedasticity with 4 lags; ${ }^{*} p<0.01,{ }^{* *} p<0.05,{ }^{* * *} p<0.1$.

Source: Own calculation.

In terms of market capitalization, the Polish stock market is the highest one in the region, as of 31 December 2014. The market capitalization of Polish stock market was of \$ 168.896 million, while for the Czech Republic stock market was of \$ 27.544 million, for Croatia stock market was of \$ 20.028 million, for Hungarian stock market was of \$ 14.513 million, for Slovenian stock market was of \$ 7.519 million, and for Slovakian stock market was of $\$ 4.732$ million.

\section{Methodology}

\subsection{Univariate models}

The proper methods designed to model and forecast variance are the well-known GARCH family models, introduced by Engle (1982) and generalized by Bollerslev (1986). A general GARCH $(p, q)$ estimation models the current conditional variance as a function of $q$ past innovations and $p$ lagged conditional variance terms. The workhorse of financial applications in modelling volatility is considered the GARCH $(1,1)$ model with quasi maximum likelihood estimation and therefore it is used here as a starting point. Furthermore, a risk 
premium $(\delta)$ is taken in account which leads to a GARCH-in-Mean (GARCH-M) estimation suggested by Engle et al. (1987).

The specification of conditional variance in GARCH-M $(1,1)$ model, which constitute the starting point for the empirical part, is given in the Equations 1 and 2 below:

$$
\begin{gathered}
R_{t}=\mu+\delta \times \sigma_{t-1}+u_{t}, u_{t} \approx N\left(0, \sigma_{t}^{2}\right) \\
\sigma_{t}^{2}=\omega+\alpha \times u_{t-1}^{2}+\beta \times \sigma_{t-1}^{2}
\end{gathered}
$$

Next, the asymmetry in volatility, i.e. the leverage effect $(\gamma)$ stated by Black (1976) have been examined through sign and size bias test proposed by Engle and $\mathrm{Ng}$ (1993) and news impact curve introduced by Pagan and Schwert (1990). Based on the results, the model selection procedure includes the following asymmetric GARCH-M models with Student's $t$ distributed errors, which capture better the fat tails of the distributions:

1. EGARCH (Nelson, 1991)

$$
\ln \left(\sigma_{t}^{2}\right)=\omega+\beta \times \ln \left(u_{t-1}^{2}\right)+\gamma \times \frac{u_{t-1}}{\sqrt{\sigma_{t-1}^{2}}}+\alpha \times\left[\frac{\left|u_{t-1}\right|}{\sqrt{\sigma_{t-1}^{2}}}-\sqrt{\frac{2}{\pi}}\right]
$$

2. GJR or Threshold-GARCH (Glosten et al., 1993)

$$
\sigma_{t}^{2}=\omega+\alpha \times u_{t-1}^{2}+\beta \times \sigma_{t-1}^{2}+\gamma \times u_{t-1}^{2} \times d\left(u_{t-1}\right)
$$

3. APARCH (Ding et al., 1993)

$$
\sigma_{t}^{\theta}=\omega+\alpha \times\left(\left|u_{t-1}\right|-\gamma \times u_{t-1}\right)^{\theta}+\beta \times \sigma_{t-1}^{\theta}
$$

4. Threshold-CGARCH (Engle and Lee, 1993)

$$
\sigma_{t}^{2}-m_{t}=\omega+\alpha \times\left(u_{t-1}^{2}-\omega\right)+\beta \times\left(\sigma_{t-1}^{2}-\omega\right)
$$

For modelling several subsamples, the best asymmetric model has been selected both in terms of information criteria (Schwarz-Bayseian) and statistical loss function (mean squared error). In order to detect the structural breaks in the CETOP 20 Index the Iterated Cumulative Sum of Squares - ICSS (Inclan and Tiao 1994), algorithm and multiple-breaks test (Bai and Perron, 2003) have been employed.

\subsection{Multivariate models}

Since stock markets co-movements are affected by common shocks, the volatility of an index could be related to the return of another index. The multivariate ARCH effects test represent a preliminary diagnostic for employing multivariate GARCH models. Due to particular issues addressed there are many more multivariate GARCH models in comparison with the univariate ones. A comprehensive survey could be found in Bauwens et al. (2006), Silvennoinen and Teräsvirta (2008) and Xekalaki and Degiannakis (2010).

Given the advantages and drawbacks for each model, in this paper, it have been employed direct generalizations of the univariate models (vectorized GARCH, i.e. VECH; Baba, Engle, Kraft and Kroner model, i.e. BEKK), and non-linear combinations of univariate 
ARCH models (Constant Conditional Correlations, i.e. CCC-ARCH; Dynamic Conditional Correlations, i.e. DCC-ARCH).

BEKK model of Baba et al. (1991) and Engle and Kroner (1995) require that the conditional variance matrices are positive definite and is viewed as an over parameterized model. For the BEKK model the natural multivariate extension of the GARCH $(1,1)$ model in Equation 2 is:

$$
H_{t}=C^{\prime} C+A^{\prime} u_{t-1} u_{t-1}^{\prime} A+B^{\prime} H_{t-1} B
$$

where $C$ is a lower triangular matrix with $(n /(n+1) / 2)$ parameters, $A$ and $B$ denote $(n \times n)$ matrices with $n^{2}$ parameters each.

VECH model of Bollerslev et al. (1988) uses a vectorized representation of the conditional covariance matrix and does not guarantee that the resulting conditional covariance matrices are positive definite. A simpler expression for $H_{t}$ can be obtained through the use of the vech(.) operator that stacks the columns of an $(n \times n)$ square matrix from the diagonal downwards into an $(n /(n+1) / 2) \times 1$ vector. Equation 7 is thus rewritten as:

$$
\operatorname{vech}\left(H_{t}\right)=\operatorname{vech}\left(C^{\prime} C\right)+\tilde{A} \times \operatorname{vech}\left(u_{t-1} u_{t-1}^{\prime}\right)+\tilde{D} \times \operatorname{vech}\left(\tilde{u}_{t-1} \tilde{u}_{t-1}^{\prime}\right)+\tilde{B} \times \operatorname{vech}\left(H_{t-1}\right)
$$

where vech $\left(C^{\prime} C\right)$ is an $(n /(n+1) / 2) \times 1$ parameter vector, $\tilde{A}$ and $\tilde{B}$ are parameter matrices of dimension $(n /(n+1) / 2 \times n /(n+1) / 2)$.

In the CCC model of Bollerslev (1990) univariate ARCH models are estimated for each asset and the correlation matrix is then estimated. The time-varying conditional covariances

are parameterized to the product of the corresponding conditional standard deviations. Let us assume that the covariance matrix can be decomposed into $H_{t}=\sum_{t}^{1 / 2} R \sum_{t}^{1 / 2}$, where $\sum_{t}^{1 / 2}$ is the diagonal matrix with conditional standard deviations along the diagonal, i.e. $\sum_{t}^{1 / 2}=\operatorname{diag}\left(\sigma_{1 t}, \sigma_{2 t}, \ldots, \sigma_{n t}\right)$ and $R_{t}$ is the matrix of conditional correlations. The constant conditional correlation model assumes that the matrix of conditional correlations is a timeinvariant matrix, $C$, so that the temporal variation of $H_{t}$ can be determined solely by the conditional variances:

$$
H_{t}=\sum_{t}^{1 / 2} R \sum_{t}^{1 / 2}
$$

As the hypothesis of constancy of correlation was found not to be supported in various applied contexts, Engle (2002) proposed a dynamic conditional correlation ARCH model which is estimated, in two steps. In the first step a series of univariate GARCH models are estimated, whereas in the second, using the residuals resulting from the first step, the conditional correlation is estimated.

The success of the DCC-ARCH model depends on the estimation of extremely large time-varying covariance matrices. Engle proposed the use of the decomposed covariance matrix $H_{t}=\sum_{t}^{1 / 2} R \sum_{t}^{1 / 2}$ with a time-varying correlation matrix of the form:

$$
R_{t}=Q_{t}^{*-1 / 2} Q_{t} Q_{t}^{*-1 / 2}
$$

The conditional variances, $\sigma_{i t}^{2}$ are estimated as univariate $\operatorname{GARCH}(1,1)$ models, allowing for different lag lengths for each series $i=1,2, \ldots, n$. The correlation matrix, $Q_{t}=\left(q_{i j t}\right)$ is computed using: 


$$
Q_{t}=\left(1-\sum_{m=1}^{q} \alpha_{m}-\sum_{c=1}^{p} \beta_{c}\right) \bar{Q}+\sum_{m=1}^{q} \alpha_{m}\left(z_{t-m} z_{t-m}^{\prime}\right)+\sum_{c=1}^{p} \beta_{c} Q_{t-c}
$$

where $z_{t}$ are the residuals standardized by their conditional standard deviation, i.e. $z_{t}=\left(z_{1 t}, z_{2 t}, \ldots, z_{n t}\right)^{\prime}=\left(u_{1 t} \sigma_{1 t}^{-1}, u_{2 t} \sigma_{2 t}^{-1}, \ldots, u_{n t} \sigma_{n t}^{-1}\right), \bar{Q}$ is the unconditional covariance of the standardized residuals and $Q_{t}^{*-1 / 2}$ is a diagonal matrix composed of the squared roots of the inverse of the diagonal elements of $Q_{t}$, i.e. $Q_{t}^{*-1 / 2}=\left(\sigma_{11 t}^{-1 / 2}, \sigma_{22 t}^{-1 / 2}, \ldots, \sigma_{n n t}^{-1 / 2}\right)$. The asymmetric model ADCC of Cappiello et al. (2006) introduces asymmetries in the correlation dynamics.

\section{Empirical Results}

\subsection{Univariate models}

The results of the GARCH-M $(1,1)$ specification with the Student $t$ distribution and conditional standard deviation term in the mean are reported in Table 2, column 2.

Table 2 | Univariate GARCH-M Models

\begin{tabular}{|l|c|c|c|c|c|}
\hline Parameters & GARCH-M & EGARCH-M & TGARCH-M & APARCH-M & TCGARCH-M \\
\hline $\boldsymbol{\alpha}$ & $\begin{array}{c}0.078^{*} \\
(0.009)\end{array}$ & $\begin{array}{c}0.158^{*} \\
(0.017)\end{array}$ & $\begin{array}{c}0.040^{*} \\
(0.011)\end{array}$ & $\begin{array}{c}0.077^{*} \\
(0.011)\end{array}$ & $\begin{array}{c}-0.038 \\
(0.030)\end{array}$ \\
\hline $\boldsymbol{\beta}$ & $\begin{array}{l}0.905^{*} \\
(0.010)\end{array}$ & $\begin{array}{c}0.982^{*} \\
(0.003)\end{array}$ & $\begin{array}{c}0.901^{*} \\
(0.011)\end{array}$ & $\begin{array}{c}0.905^{*} \\
(0.011)\end{array}$ & $\begin{array}{c}-0.580^{* * *} \\
(0.350)\end{array}$ \\
\hline $\boldsymbol{\gamma}$ & - & $-0.051^{*}$ & $\begin{array}{c}0.073^{*} \\
(0.015)\end{array}$ & $\begin{array}{c}0.279^{*} \\
(0.074)\end{array}$ & $\begin{array}{c}0.065 \\
(0.042)\end{array}$ \\
\hline $\boldsymbol{\delta}$ & - & $-0.009)$ & -0.053 & -0.055 & $-0.028^{* * *}$ \\
\hline SSB & -0.025 & -0.060 & $(0.058)$ & $(0.058)$ & $(0.058)$ \\
\hline SBC & $(0.058)$ & $(0.054)$ & - & - & - \\
\hline $\bar{\Psi}_{(S E)(i)}$ & $204.698^{*}$ & - & -5.852 & -5.849 & -5.841 \\
\hline
\end{tabular}

Note: Standard errors in parentheses; The best-performing model is shown in bold face; SSB - sign and size bias test for asymmetries in volatility; SBC - Schwarz's Bayesian criterion; $\bar{\Psi}_{(S E)(i)}$ - the mean squared error loss function. The notations correspond to Equations $1-6 ;{ }^{*} p<0.01,{ }^{* *} p<0.05,{ }^{* * *} p<0.1$.

Source: Own calculations.

The model is highly persistent with the sum of the ARCH $(\alpha)$ and the GARCH $(\beta)$ coefficients closer to unity (0.983). Furthermore, $\beta$ is significantly larger than $\alpha$, suggesting the superiority of the impact of old news on volatility. Related to the risk premium, there is no feedback from the conditional variance to the conditional mean, since the estimated parameter of the mean $(\delta)$ is insignificant. 
In the financial world it is well known that for the same magnitude of the shocks volatility is asymmetric, namely it may raise more for the negative news than for the positive news. The sign and size test for an asymmetric effect (SSB) is employed, and reject the null of no sign and size bias. The asymmetric effect is explored in depth by using news impact curve and underscore the findings from the SSB test ${ }^{2}$. These results constitute the motivation for employing univariate asymmetric GARCH-M models (Table 2, columns $3-6)$. For all models the asymmetric effect $(\gamma)$ is significant, barring Component GARCH-M with Threshold. The model that best fits the data is considered TGARCH-M $(1,1)$ for both Schwarz's Bayesian criterion and the mean squared error loss function.

Given the long time period examined, it is of importance if potential breaks affect the analysis. In this respect, a structural break points analysis was employed. Different criteria give different results here, as ICSS chooses 7 breaks, and Bai-Perron (with both criteria) chooses 4 breaks. Furthermore, for ICSS, 4 out of 7 breaks are around the breaks suggested by Bai-Perron. For various reasons, it makes sense to start with a smaller number of breaks and expand it if that seems to be needed. Thus Bai-Perron test revealed four structural breaks in the unconditional volatility of stock market return in CEE, specifically on $4^{\text {th }}$ November 2004, $20^{\text {th }}$ October 2006, $6^{\text {th }}$ October 2008 and $9^{\text {th }}$ September 2011. Figure 1 includes grid lines for all breaks suggested, where it could be noticed that first two breaks are characterized by a decrease in volatility and the last two by an increase.

The first break is identified around November 2004 and represents the effect of EU accession, which impacted the economies from Central Europe. Second break is identified around October 2006 and could be related to the ECB decision to increase the key interest rates, i.e. rate of the main refinancing operations, rate of marginal lending facility and deposit facility. Third break is identified around October 2008, where the economies could be suffering from the consequences of the financial crisis (Lehman Brothers bankruptcy). Finally, the break identified around September 2011 could be explained through the oil and euro sovereign crisis. Loosely speaking, there are some theorists who believe that rising oil prices represent the main cause of recessions. Given these set of events, the four structural breaks characterized by increased and reduced volatility, it makes sense to divide the sample in 5 sub-samples.

Table 3 reports the unconditional variance using TGARCH-M(1,1) model with Student $t$ distribution both over the full sample and sub-samples suggested by the break dates aforementioned.

The results confirm that structural breaks are a relevant issue of stock market returns and several remarks could be drawn up. First, all sub-samples are characterized by conditional heteroskedasticity, due to high levels of persistence. Second, one can observe the insignificance of asymmetric effect during rapid growth period of capital markets (subsample 1: 31 January 2002-4 November 2004). This behaviour of asymmetric term for sub-sample 1 supports the greed sentiment that dominates the market and ignores the fear sentiment. Third, the magnitude evolution of asymmetric term with a maximum in subsample 3, which is consistent with the pre-crisis period raise a flag, that if higher levels might be considered as a valid signal for crisis.

2 The news impact curve graphs are not displayed here but they are made available upon request. 


\begin{tabular}{|c|c|c|c|c|c|c|}
\hline Parameters & FULL & SS1 & SS2 & SS3 & SS4 & SS5 \\
\hline \multirow{2}{*}{$a$} & $0.040^{*}$ & 0.040 & 0.027 & $-0.046^{* *}$ & $0.051^{* *}$ & -0.002 \\
\hline & $(0.011)$ & $(0.025)$ & $(0.037)$ & $(0.021)$ & $(0.025)$ & $(0.012)$ \\
\hline \multirow{2}{*}{$\beta$} & $0.901^{*}$ & $0.909^{*}$ & $0.851^{*}$ & $0.888^{*}$ & $0.894^{*}$ & $0.957^{*}$ \\
\hline & $(0.011)$ & $(0.030)$ & (0.049) & (0.039) & $(0.018)$ & $(0.010)$ \\
\hline \multirow{2}{*}{$\gamma$} & $0.073^{*}$ & 0.039 & $0.101 * *$ & $0.235^{*}$ & $0.078^{* *}$ & $0.047^{* *}$ \\
\hline & $(0.015)$ & $(0.028)$ & $(0.045)$ & $(0.057)$ & $(0.035)$ & (0.019) \\
\hline \multirow{2}{*}{$\delta$} & -0.053 & -0.291 & $-0.515^{* *}$ & 0.033 & -0.020 & 0.121 \\
\hline & $(0.058)$ & $(0.206)$ & $(0.241)$ & $(0.165)$ & (0.096) & $(0.135)$ \\
\hline $\begin{array}{l}\text { Number of } \\
\text { Observations }\end{array}$ & 3,406 & 721 & 512 & 512 & 765 & 900 \\
\hline
\end{tabular}

Note: Robust standard errors in parentheses. The best-performing model is shown in bold face. The notations correspond to Equations 1-6; ${ }^{*} p<0.01,{ }^{* *} p<0.05,{ }^{* * *} p<0.1$.

Source: Own calculations.

\subsection{Multivariate models}

A preliminary test suggests the presence of multivariate $\mathrm{ARCH}$ effects and therefore bivariate VECH-GARCH, BEKK-GARCH, CCC-GARCH and DCC-GARCH models are estimated for the multivariate approach. All models were estimated with asymmetric effects, Student $t$ distribution and robust standard errors. The estimates for VECH and BEKK are reported in Table 4.

For both models and pairs considered (CEE-EM, CEE-DM), the diagonal matrix elements are significant, reinforcing the persistence and asymmetric behaviour. Regarding the off-diagonal matrix elements, different behaviour is observed. On the one hand, for CEE-EM pair, the lower elements are significant (except $\gamma_{21}$ for BEKK model) and the upper ones are insignificant. This means that there are one way cross-effects, i.e. the asymmetric volatility transmission mechanism is observed from the CEE to emerging markets, and not vice versa. On the other hand, for CEE-DM pair no off-diagonal elements are significant, suggesting no cross-effects between the indexes. This leads to a preliminary conclusion that CEE stock markets are correlated with emerging, rather than developed markets.

However, VECH and BEKK models are less preferable in empirical work, since they parameterize conditional variances and therefore conditional correlations have to be determined indirectly. In this respect, the analysis has been extended to models that deal with conditional correlations, either constant, or dynamic. Table 5 presents the estimates for CCC and DCC models, where again the long-run persistence is supported. Furthermore, for both pairs the correlation coefficient $\left(\rho_{2,1}\right)$ estimated under CCC model is significantly positive and lower than the unconditional correlation. The assumption of constant conditional correlation is rejected by the DCC model, where the parameters that govern the GARCH process of the $\mathrm{Q}$ sequence $\left(\theta_{1}\right.$ and $\left.\theta_{2}\right)$ are significant. 


\begin{tabular}{|c|c|c|c|c|c|c|c|c|c|}
\hline Variables & \multicolumn{2}{|c|}{ C } & \multicolumn{2}{|c|}{ A } & \multicolumn{2}{|c|}{ B } & \multicolumn{2}{|c|}{ D } & SBC \\
\hline \multicolumn{10}{|l|}{ VECH } \\
\hline \multirow{4}{*}{$\begin{array}{l}\text { CEE } \\
\text { versus } \\
\text { EM }\end{array}$} & $3.49 \mathrm{E}-06^{*}$ & - & $0.029^{*}$ & - & $0.923^{*}$ & - & $0.049^{*}$ & - & \multirow{4}{*}{-12.701} \\
\hline & $(0.80 \mathrm{E}-06)$ & - & $(0.007)$ & - & $(0.010)$ & - & $(0.011)$ & - & \\
\hline & $1.46 \mathrm{E}-06^{*}$ & $2.17 \mathrm{E}-06^{*}$ & $0.023^{*}$ & $0.029^{*}$ & $0.928^{*}$ & $0.914^{*}$ & $0.046^{*}$ & $0.066^{*}$ & \\
\hline & $(0.34 \mathrm{E}-06)$ & $(0.49 \mathrm{E}-06)$ & $(0.007)$ & $(0.007)$ & $(0.008)$ & $(0.009)$ & $(0.011)$ & $(0.015)$ & \\
\hline \multirow{4}{*}{$\begin{array}{l}\text { CEE } \\
\text { versus } \\
\text { DM }\end{array}$} & $3.10 \mathrm{E}-06^{*}$ & - & $0.035^{*}$ & - & $0.921^{*}$ & - & $0.048^{*}$ & - & \multirow{4}{*}{-13.022} \\
\hline & $(0.86 \mathrm{E}-06)$ & - & $(0.007)$ & - & $(0.012)$ & - & $(0.015)$ & - & \\
\hline & $0.60 \mathrm{E}-06^{*}$ & $0.82 \mathrm{E}-06^{*}$ & $0.019^{*}$ & $0.011^{* * *}$ & $0.933^{*}$ & $0.928^{*}$ & $0.057^{*}$ & $0.092^{*}$ & \\
\hline & $(0.21 \mathrm{E}-06)$ & $(0.21 \mathrm{E}-06)$ & $(0.005)$ & $(0.006)$ & $(0.009)$ & $(0.011)$ & $(0.012)$ & $(0.016)$ & \\
\hline \multicolumn{10}{|l|}{ BEKK } \\
\hline \multirow{4}{*}{$\begin{array}{l}\text { CEE } \\
\text { versus } \\
\text { EM }\end{array}$} & $1.49 \mathrm{E}-03^{*}$ & - & $0.144^{*}$ & -0.061 & $0.981^{*}$ & 0.027 & $0.143^{*}$ & 0.060 & \multirow{4}{*}{-12.699} \\
\hline & $(0.30 \mathrm{E}-03)$ & - & $(0.048)$ & $(0.041)$ & $(0.013)$ & $(0.020)$ & $(0.053)$ & $(0.041)$ & \\
\hline & $0.69 \mathrm{E}-03^{* *}$ & $1.57 \mathrm{E}-03^{*}$ & $0.100^{* * *}$ & $0.177^{*}$ & $-0.043^{* * * *}$ & $0.920^{*}$ & 0.104 & $0.286^{*}$ & \\
\hline & $(0.33 E-03)$ & $(0.26 \mathrm{E}-03)$ & $(0.053)$ & $(0.044)$ & $(0.025)$ & $(0.024)$ & $(0.082)$ & (0.069) & \\
\hline \multirow{4}{*}{$\begin{array}{l}\text { CEE } \\
\text { versus } \\
\text { DM }\end{array}$} & $1.62 \mathrm{E}-03^{*}$ & - & $0.201^{*}$ & 0.001 & $0.964^{*}$ & $-0.6 \mathrm{E}-03$ & $0.163^{*}$ & 0.017 & \multirow{4}{*}{-13.016} \\
\hline & $(0.23 E-03)$ & - & $(0.046)$ & $(0.025)$ & $(0.007)$ & $(0.008)$ & $(0.038)$ & $(0.023)$ & \\
\hline & $0.46 \mathrm{E}-03^{* *}$ & $0.82 \mathrm{E}-03^{*}$ & -0.014 & $0.106^{*}$ & -0.014 & $0.959^{*}$ & 0.128 & $0.311^{*}$ & \\
\hline & $(0.18 \mathrm{E}-03)$ & $(0.20 \mathrm{E}-03)$ & $(0.166)$ & $(0.054)$ & $(0.016)$ & $(0.013)$ & $(0.079)$ & $(0.036)$ & \\
\hline
\end{tabular}

Note: Robust Standard errors in parentheses.

$C=\left[\begin{array}{cc}\omega_{11} & 0 \\ \omega_{21} & \omega_{22}\end{array}\right], A=\left[\begin{array}{ll}\alpha_{11} & \alpha_{12} \\ \alpha_{21} & \alpha_{22}\end{array}\right], B=\left[\begin{array}{ll}\beta_{11} & \beta_{12} \\ \beta_{21} & \beta_{22}\end{array}\right], D=\left[\begin{array}{ll}\gamma_{11} & \gamma_{12} \\ \gamma_{21} & \gamma_{22}\end{array}\right]$ are the coefficient matrices from

Equation 7 and Equation 8; ${ }^{*} p<0.01,{ }^{* *} p<0.05,{ }^{* * *} p<0.1$.

Source: Own calculations.

Therefore, one can highlight a contagion effect between CEE and both emerging and developed markets, i.e. a joint risk due to shifts of international capital could affect them similarly. The time-varying conditional correlation is given in Figure 2. 
Table 5 | CCC and DCC Models

\begin{tabular}{|c|c|c|c|c|c|c|c|c|c|}
\hline Variables & $\omega$ & $a$ & $\beta$ & $\alpha+\beta$ & 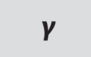 & $\rho_{2,1}$ & $\theta_{1}$ & $\theta_{2}$ & $S B C$ \\
\hline \multicolumn{10}{|l|}{ CCC } \\
\hline \multirow{4}{*}{$\begin{array}{l}\text { CEE } \\
\text { versus } \\
\text { EM }\end{array}$} & $5.14 \mathrm{E}-06^{*}$ & $0.032^{*}$ & $0.910^{*}$ & 0.942 & $0.047^{*}$ & $0615^{*}$ & - & - & \multirow{4}{*}{-12.691} \\
\hline & $(1.08 \mathrm{E}-06)$ & $(0.008)$ & $(0.012)$ & - & $(0.012)$ & & - & - & \\
\hline & $3.18 \mathrm{E}-06^{*}$ & $0.022^{*}$ & $0.904^{*}$ & 0.926 & $0.079^{*}$ & ) & - & - & \\
\hline & $(0.54 \mathrm{E}-06)$ & $(0.007)$ & $(0.010)$ & - & $(0.014)$ & & - & - & \\
\hline \multirow{4}{*}{$\begin{array}{l}\text { CEE } \\
\text { versus } \\
\text { DM }\end{array}$} & $5.43 \mathrm{E}-06^{*}$ & $0.039^{*}$ & $0.902^{*}$ & 0.941 & $0.049^{*}$ & $0.540^{*}$ & - & - & \multirow{4}{*}{-12.995} \\
\hline & $(1.27 \mathrm{E}-06)$ & $(0.009)$ & $(0.015)$ & - & $(0.015)$ & & - & - & \\
\hline & $1.30 \mathrm{E}-06^{*}$ & 0.002 & $0.922^{*}$ & 0.922 & $0.106^{*}$ & $(0.014)$ & - & - & \\
\hline & $(0.25 \mathrm{E}-06)$ & $(0.007)$ & $(0.010)$ & - & $(0.016)$ & & - & - & \\
\hline \multicolumn{10}{|l|}{ DCC } \\
\hline \multirow{4}{*}{$\begin{array}{l}\text { CEE } \\
\text { versus } \\
\text { EM }\end{array}$} & $3.79 \mathrm{E}-06^{*}$ & $0.033^{*}$ & $0.921^{*}$ & 0.954 & $0.049^{*}$ & - & $0010^{*}$ & (0076* & \multirow{4}{*}{-12.704} \\
\hline & $(0.86 \mathrm{E}-06)$ & $(0.007)$ & $(0.011)$ & - & $(0.012)$ & - & & & \\
\hline & $2.33 \mathrm{E}-06^{*}$ & $0.027^{*}$ & $0.914^{*}$ & 0.941 & $0.074^{*}$ & - & ( & $(0,010)$ & \\
\hline & $(0.49 E-06)$ & $(0.006)$ & $(0.010)$ & - & $(0.014)$ & - & $10.007)$ & (1) & \\
\hline \multirow{4}{*}{$\begin{array}{l}\text { CEE } \\
\text { versus } \\
\text { DM }\end{array}$} & $3.60 \mathrm{E}-06^{*}$ & $0.039^{*}$ & $0.916^{*}$ & 0.955 & $0.049^{*}$ & - & ( $010^{*}$ & $0070^{*}$ & \multirow{4}{*}{-13.028} \\
\hline & $(0.95 E-06)$ & $(0.009)$ & $(0.013)$ & - & $(0.014)$ & - & & & \\
\hline & $0.87 \mathrm{E}-06^{*}$ & 0.004 & $0.932^{*}$ & 0.932 & $0.100^{*}$ & - & $(\cap 006)$ & (7م00 & \\
\hline & $(0.21 \mathrm{E}-06)$ & $(0.007)$ & (0.009) & - & $(0.016)$ & - & & & \\
\hline
\end{tabular}

Note: Robust Standard errors in parentheses. The notations correspond to Equation 9 and Equation 10; ${ }^{*} \mathrm{p}<0.01,{ }^{* *} \mathrm{p}<0.05,{ }^{* * *} \mathrm{p}<0.1$.

Source: Own calculations.

Figure 2 | Dynamic Conditional Correlations
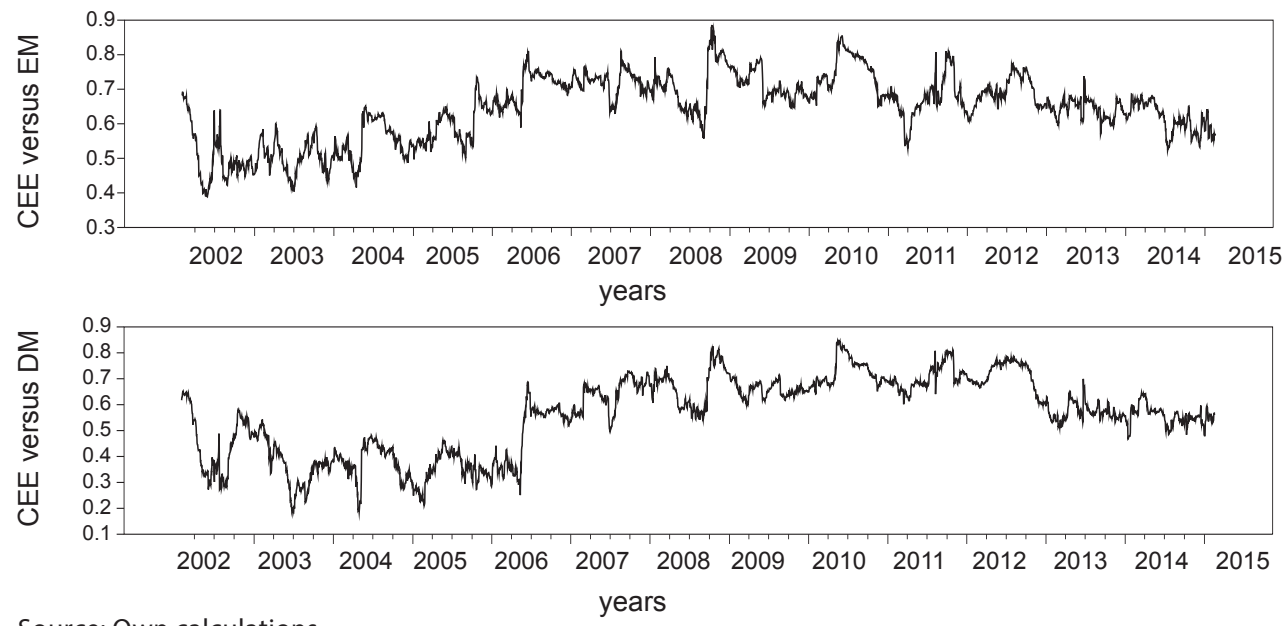

Source: Own calculations. 
For CEE-EM pair the results suggest that the stock market co-movements range between $0.38-0.88$, whereas for CEE-DM pair the results suggest that the stock market comovements range between 0.18-0.84. Overall, the CEE stock markets are more correlated with emerging, rather than developed market (an average of 0.64 in comparison with 0.56 ), and react significantly during crisis period (maximum value 0.88 is recorded in October 2008). This means that the CEE group and other emerging markets could not be considered simultaneously for portfolio diversification. Furthermore, for both pairs, the correlation becomes suddenly stronger for the break dates characterized by an increase in volatility ( $6^{\text {th }}$ October 2008 and $9^{\text {th }}$ September 2011).

Overall, the results support previous findings from the empirical work of financial economics, which have employed GARCH models. Concretely, like Patev et al. (2006) the CEE stock markets exhibit an asymmetric volatility, in favour of leverage hypothesis. Furthermore, like Syllignakis and Kouretas (2011), the volatility increases over time, particularly when international factors dominate the national ones, and influence stock markets (Wang and Moore, 2008; Demiralay and Bayraci, 2015). Finally, the CEE stock markets analysed tend to be correlated with both emerging markets and developed markets, but with a higher degree for emerging markets.

\section{Conclusions}

The main goal of the paper was to examine stock market volatility for Central European stock markets, given that volatility serves as a measure of both financial markets and economies vulnerability and guide policymakers to design proper policies.

In the univariate approach, the results indicate the persistence of the GARCH effect, and do not reject the leverage effect hypothesis, i.e. asymmetric behaviour. Therefore, one can reinforce that for the Central European stock markets the bad news generate more volatility than the good news. Since the period examined (from 2002 up to 2015) experienced several international events, i.e. EU accession, financial crisis, oil crisis, it is worth to establish whether accounting for structural breaks would affect estimates of volatility. For a lower level overlapping rapid growth period, the asymmetric coefficient is insignificant, consistent with greed sentiment, whereas for a higher level with a maximum overlapping pre-crisis period the asymmetric coefficient is significant.

In the bivariate approach that parameterize conditional variances (VECH, BEKK) the results suggest that the asymmetric volatility transmission mechanism is observed from the CEE to the emerging markets but not vice versa, and no cross-effects for CEE-developed markets pair. This leads to a preliminary conclusion that CEE stock markets are correlated with emerging rather than developed markets. Therefore the investors should pay increased attention to the diversification principle when several stock markets are considered.

For the models that consider conditional correlations (CCC and DCC), the long-run persistence is supported. On the one hand, the correlation coefficient estimated under the CCC model is significantly positive and lower than the unconditional correlation. On the other hand, constant conditional correlation is rejected by the DCC model, where the parameters that govern the GARCH process are significant. Finally, the dynamic conditional correlation indicates that the correlation is significantly higher for the break dates characterized by an increase in volatility. 


\section{References}

Baba, Y., Engle, R. F., Kraft, D. F., Kroner, K. F. (1991). Multivariate Simultaneous Generalized ARCH. Dept. of Economics, UCSD, manuscript.

Bai, J., Perron, P. (2003). Computation and Analysis of Multiple Structural Change Models. Journal of Applied Econometrics, 18(1), 1-22, http://dx.doi.org/10.1002/jae.659

Basel Committee on Banking Supervision (2011). Revisions to the Basel II Market Risk Framework. Bank for International Settlements.

Bauwens, L., Laurent, S., Rombouts, J. V. K. (2006). Multivariate GARCH Models: A survey. Journal of Applied Econometrics, 21(1), 79-109, http://dx.doi.org/10.1002/jae.842

Black, F. (1976). Studies of Stock Price Volatility Changes. In: Proceedings of the 1976 Meeting of the Business and Economic Statistics Section, American Statistical Association, Washington, D.C. $177-181$.

Bollerslev, T. (1986). Generalized Autoregressive Conditional Heteroscedasticity. Journal of Econometrics, 31(3), 307-327, http://dx.doi.org/10.1016/0304-4076(86)90063-1

Bollerslev, T., Engle, R. F., Wooldridge, J. M. (1988). A Capital Asset Pricing Model with Time Varying Covariances. Journal of Political Economy, 96(1), 116-131, http://dx.doi.org/10.1086/261527

Bollerslev, T. (1990). Modelling the Coherence in Short-Run Nominal Exchange Rates:

A Multivariate Generalized ARCH Model. Review of Economics and Statistics, 72(3), 498-505, http://dx.doi.org/10.2307/2109358

Cappiello, L., Engle, R. F., Sheppard, K. (2006). Asymmetric Dynamics in the Correlations of Global Equity and Bond Returns. Journal of Financial Econometrics, 4(4), 537-572, http://dx.doi.org/10.1093/jjfinec/nbl005

Dajčman, S. (2013). Interdependence between Some Major European Stock Markets - A Wavelet Lead/Lag Analysis. Prague Economic Papers, 22(1), 28-49, http://dx.doi.org/10.18267/j.pep.439

Demiralay, S., Bayraci, S. (2015). Central and Eastern European Stock Exchanges under Stress: A Range-Based Volatility Spillover Framework. Czech Journal of Economics and Finance, 65(5), 411-430, Available at: http://journal.fsv.cuni.cz/storage/1341_demiralay.pdf

Ding, Z., Granger, C. W. J., Engle, R. F. (1993). A Long Memory Property of Stock Market Returns and a New Model. Journal of Empirical Finance, 1(1), 83-106, http://dx.doi.org/10.1016/09275398(93)90006-d

Engle, R. F. (1982). Autoregressive Conditional Heteroscedasticity with Estimates of the Variances of United Kingdom Inflation. Econometrica, 50(4), 987-1007, http://dx.doi.org/10.2307/1912773

Engle, R. F., Lilien, D. M., Robins, R. P. (1987). Estimating Time Varying Risk Premia in the Term Structure: The ARCH-M Model. Econometrica, 55(2), 391-407, http://dx.doi.org/10.2307/1913242

Engle, R. F., Ng, V. K. (1993). Measuring and Testing the Impact of News on Volatility. Journal of Finance, 48(5), 1749-1778, http://dx.doi.org/10.2307/2329066

Engle, R. F., Lee, G. G. J. (1993). A Permanent and Transitory Component Model of Stock Return Volatility. Department of Economics, University of California, San Diego. Discussion Paper No. 9244.

Engle, R. F., Kroner, F. K. (1995). Multivariate Simultaneous Generalized ARCH. Econometric Theory, 11(1), 122-150, http://dx.doi.org/10.1017/s0266466600009063.

Engle, R. F. (2002). Dynamic Conditional Correlation: A Simple Class of Multivariate GARCH Models. Journal of Business and Economic Statistics, 20(3), 339-350, http://dx.doi.org/10.1198/073500102288618487 
Gjika, D., Horváth, R. (2013). Stock Market Comovements in Central Europe: Evidence from the Asymmetric DCC Model. Economic Modelling, 33, 55-64, http://dx.doi.org/10.1016/j. econmod.2013.03.015

Glosten, L. R., Jagannathan, R., Runkle, D. E. (1993). On the Relation between the Expected Value and the Volatility of the Nominal Excess Return on Stocks. The Journal of Finance, 48(5), 1779-1801, http://dx.doi.org/10.1111/j.1540-6261.1993.tb05128.x

Guidi, F., Ugur, M. (2014). An Analysis of South-Eastern European Stock Markets: Evidence on Cointegration and Portfolio Diversification Benefits. Journal of International Financial Markets, Institutions and Money, 30, 119-136, http://dx.doi.org/10.1016/j.intfin.2014.01.007

Harrison, B., Moore, W. (2012). Forecasting Stock Market Volatility in Central and Eastern European Countries. Journal of forecasting, 31(6), 490-503, http://dx.doi.org/10.1002/for.1214

Horváth, R., Petrovski, D. (2013). International Stock Market Integration: Central and South Eastern Europe Compared. Economic Systems, 37(1), 81-91, http://dx.doi.org/10.1016/j. ecosys.2012.07.004

Inclan, C., Tiao, G. C. (1994). Use of Cumulative Sums of Squares for Retrospective Detection of Changes of Variance. Journal of the American Statistical Association, 89(427), 913-923, http://dx.doi.org/10.1080/01621459.1994.10476824

Kasch-Haroutonian, M., Price, S. (2001). Volatility in the Transition Markets of Central Europe. Applied Financial Economics, 11(1), 93-105, http://dx.doi.org/10.1080/09603100150210309

Murinde, V., Poshakwale, S. (2001). Volatility in the Emerging Stock Markets in Central and Eastern Europe: Evidence on Croatia, Czech Republic, Hungary, Poland, Russia and Slovakia. European Research Studies, 4(3/4), 73-101. Available at: http://www.ersj.eu/repec/ers/ papers/01_34_p6.pdf

Nelson, D. B. (1991). Conditional Heteroskedasticity in Asset Returns: A New Approach. Econometrica, 59(2), 347-370, http://dx.doi.org/10.2307/2938260

Pagan, A. R., Schwert, G. W. (1990). Alternative Models for Conditional Stock Volatilities. Journal of Econometrics, 45(1-2), 267-290, http://dx.doi.org/10.1016/0304-4076(90)90101-x

Patev, P., Kanaryan, N., Lyroudi, K. (2006). Stock Market Crises and Portfolio Diversification in Central and Eastern Europe. Managerial Finance, 32(5), 415-432, http://dx.doi. org/10.1108/03074350610657436

Silvennoinen, A., Teräsvirta, T. (2008). Mulivariate GARCH Models, in Andersen, T. G., Davis, R. A., Kreiss J-P., and Mikosch T., ed., Handbook of Financial Time Series. New York: Springer, pp. 201-229.

Syllignakis, M. N., Kouretas, G. P. (2011). Dynamic Correlation Analysis of Financial Contagion: Evidence from the Central and Eastern European Markets. International Review of Economics and Finance, 20(4), 717-732, http://dx.doi.org/10.1016/j.iref.2011.01.006

Wang, P., Moore, T. (2008). Stock Market Integration for the Transition Economies: Time-Varying Conditional Correlation Approach. The Manchester School Supplement, 76, 116-133, http://dx.doi.org/10.1111/j.1467-9957.2008.01083.x

Wang, P., Moore, T. (2009). Sudden Changes in Volatility: The Case of Five Central European Stock Markets. Journal of International Financial Markets, Institutions and Money, 19(1), 33-46, http://dx.doi.org/10.1016/j.intfin.2007.08.006

Xekalaki, E., Degiannakis, S. (2010). ARCH Models for Financial Applications. John Wiley and Sons, 445-475. ISBN: 978-0-470-06630-0. 